\title{
Oestrus ovis ophthalmomyiasis acquired in the UK: case report and scanning electron microscopic study
}

\author{
J D Stevens, A C E McCartney, R Howes
}

\begin{abstract}
A case of external ophthalmomyiasis acquired in the $\mathrm{UK}$ is reported. Oestrus ovis infestation of the external conjunctiva is described and a scanning electron microscopic study made of the first stage larvae. To our knowledge this represents only the third case reported of UK acquisition of ophthalmomyiasis.
\end{abstract}

A 32-year-old woman with no past ophthalmic history attended Moorfields Eye Hospital complaining that she had been sunbathing in her garden in Dorset in August when she felt a foreign-body sensation in her right eye which persisted after a fly had landed on her closed right eyelid. She was aware that she had some difficulty in brushing the fly away, and began to experience an agonising moving foreign-body sensation in the eye. She looked in a mirror and saw moving larvae and managed to remove four larvae before attending Moorfields Casualty Department later the same day.

Examination revealed three larvae moving on the surface of the conjunctiva. These were transparent, segmented, and anteriorly had black mouth parts. They were removed with a moistened cotton bud. The larvae displayed negative phototaxis, moving away from the slitlamp light beam. The tarsal conjunctiva was

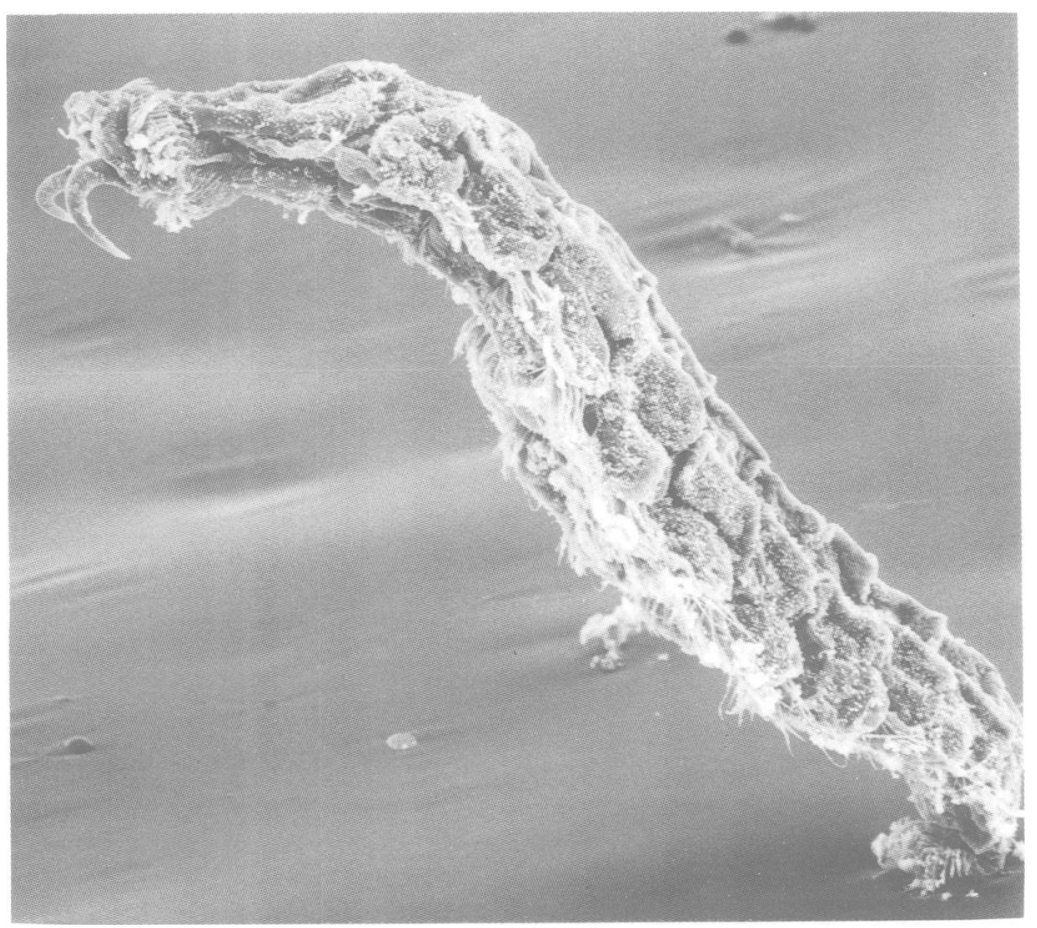

Figure 1 Scanning electron micrograph of Oestrus ovis first stage larva removed from the conjunctival fornix. The anterior end is to the left with prominent mouthpiece $(\times 140$.

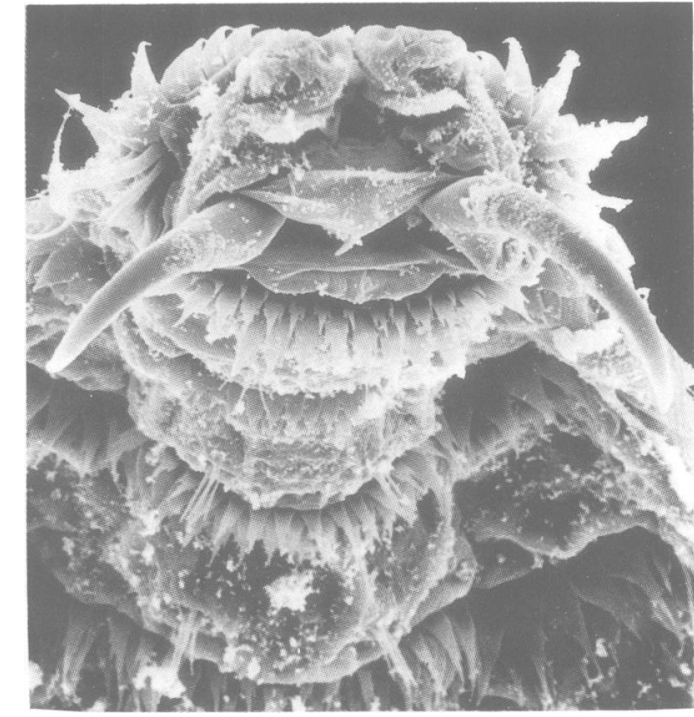

Figure 2 Enlarged view of anterior end showing mouthpiece. $(\times 340$.

mildly inflamed. There was no evidence of subconjunctival penetration by the organisms, and none was seen in the anterior or posterior chambers of the eye. Two larvae were kept for species identification and scanning electron microscopy. Treatment with prednisolone eyedrops $0.3 \%$ and chloramphenicol eyedrops four times daily was given. Review next day revealed mild irritation and a follicular conjunctival response but no further feeling of movement.

However, a new symptom of unilateral sneezing developed. Examination of the nasal passages revealed no organism and the rhinitis resolved over the next three days. On follow-up an ocular examination gave normal results.

The specimens were identified as first stage larvae of Oestrus ovis by Dr R G Adams of the Ministry of Agriculture, Fisheries, and Food.

\section{Discussion}

Ophthalmomyiasis is a condition in which the eye is invaded by larvae of the order Diptera. When larvae remain outside the eye it is termed ophthalmomyiasis externa, while penetration of the anterior or posterior chamber of the eye is termed ophthalmomyiasis interna.' Eighty species of Diptera have been known to invade man. ${ }^{2}$ Oestrus ovis, the sheep nasal bot fly, has been reported from the Mediterranean, ${ }^{3}$ Asia, and the Americas, ${ }^{+}$reflecting the distribution of sheep. Ophthalmomyiasis acquired in England has been reported before but is very rare. In 1950 Oestrus ovis was reported in England, 5 possibly being acquired in Devon, and one other case is currently being reported from Portsmouth. 


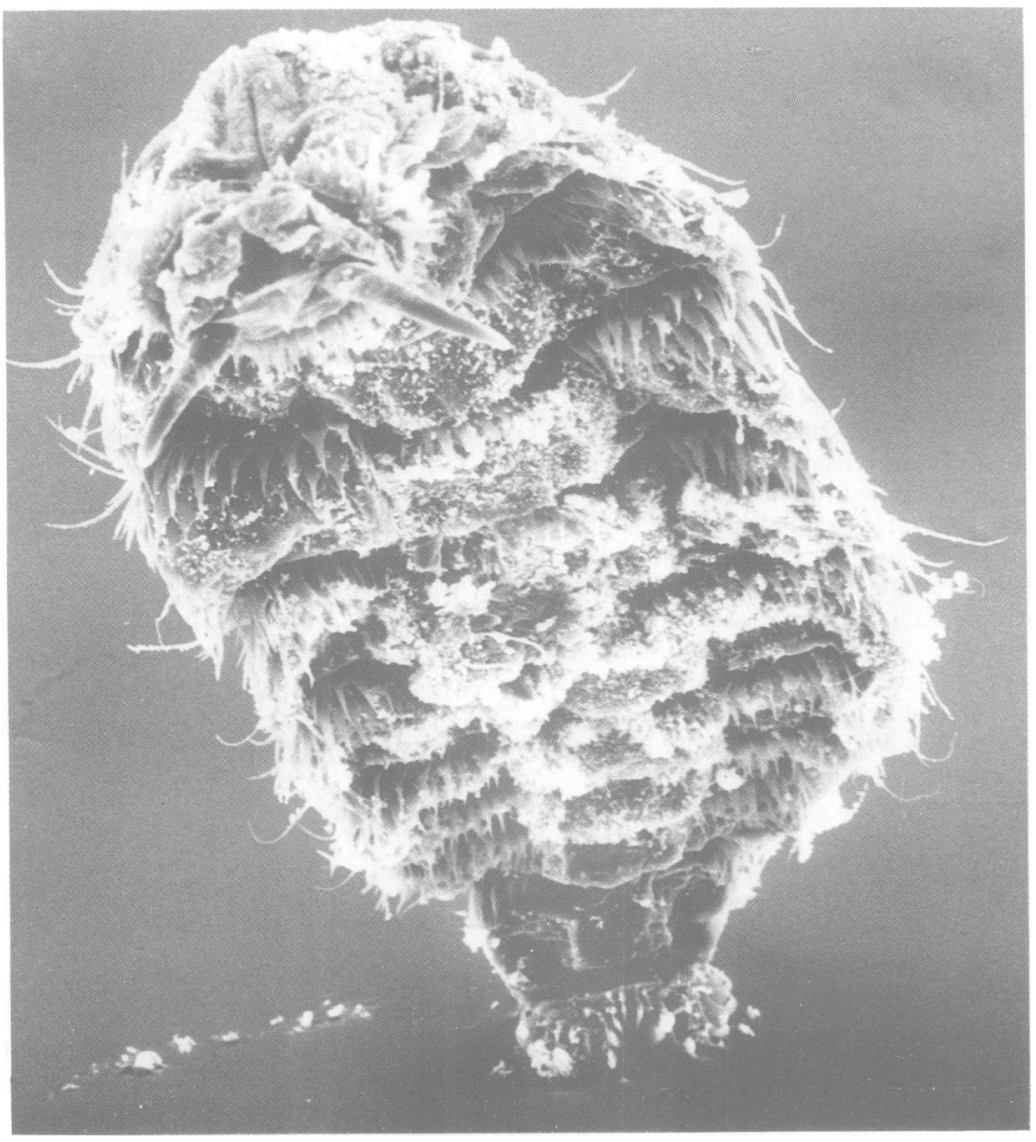

Figure 3 Anteroposterior view showing underside of larva. $(\times 140$.

Infestation by larvae has also been reported from the New Forest, Hampshire. ${ }^{6}$ Larvae may otherwise be imported into the UK. ${ }^{7}$

During the summer gravid adult females deposit their maggots on the nares of sheep and goats. Occasionally humans may become the target, and larvae may be directly deposited on the conjunctiva. The symptoms are of acute conjunctivitis, ${ }^{89}$ with soreness, lacrimation, and conjunctival injection. There may also be a follicular conjunctival reaction. ${ }^{10}$ The larvae are relatively harmless if removed promptly, and Oestrus ovis does not burrow, so infestation is limited to the outer membranes of the eye. The larvae cannot mature on the human conjunctiva, and they soon die. However, Hypoderma may penetrate the eye and cause profound damage. ${ }^{11}$ The infection of the conjunctival sac by fly larvae is rare in Western Europe but is commoner in Eastern Europe and the tropics. The symptom of rhinitis in association with the conjunctival reaction has been reported before. ${ }^{10}$ In our case no organisms were seen on nasal examination.

The help is acknowledged of Dr R G Adams, Storage Pests Department, Insect Identification Unit, ADAS Central Science Laboratory, Ministry of Agriculture, Fisheries and Food, London Road, Slough SL3 7HJ

1 Duke-Elder S. System of ophthalmology. London: Kimpton, 1965; 8: 426-9.

2 Hargreaves WH, Morrison RLG. The practice of tropical medicine. London: Staples, 1965; 403-6.

3 Le Fichoux Y, Marty P, Denis G, Courturier P, Dellamonica $P$. A case of ophthalmomyiasis in man by Oestrus ovis caught on the Nice beach, France. Acta Trop (Basel) 1981; 38: 461

4 Reingold WJ, Robin JB, Leipa D, Kondra L, Schanzlin DJ, Smith RE. Oestrus ovis ophthalmomyiasis externa. Am $\mathscr{f}$ Ophthalmol 1984; 97: 7.

5 Smith R J H. Ophthalmomyiasis in England. Br F Ophthalmo 1951; 35: 242-3.

6 Romanes GJ. Ocular myiasis. Br f Ophthalmol 1983; 67: 332.

7 Wong D. External ophthalmomyiasis caused by the sheep bot Oestrus ovis L. Brf Ophthalmol 1982; 66: 786-7.

8 Hennessy DJ, Sherrill JW, Binder PS. External ophthalmomyiasis caused by Oestrus ovis. Am $\mathcal{F}$ Ophthalmol 1977; 84: 802 .

9 Healey MC, Collins RK, Hawkins JA. Ophthalmooestriasis externa. South Med F 1980; 73: 1387

10 Mazzeo V, Ercolani D, Trombetti D, Todeschini R, Gaiba G. External ophthalmomyiasis. Report of four cases. In Ophthalmol 1987; 11: 73-6.

11 Mason GI. Bilateral ophthalmomyiasis interna. Am f Ophthalmol 1981; 91: 65 . 